\title{
«Северные» элементы в фауне водных жесткокрылых (Insecta: Coleoptera) Саратовской области
}

\author{
А.C. Сажнев \\ Институт биологии внутренних вод им. И.Д. Папанина Российской академии наук, \\ Россия, 152742, Ярославская область, п. Борок, 135 \\ E-mail: sazh@list.ru
}

\begin{abstract}
Аннотация. Географическое расположение и разнообразие природных зон (лесостепь, степь, полупустыня) Саратовской области создает уникальные условия формирования фауны водных жесткокрылых региона. Вследствие проникновения островных и пойменных лесов (и связанных с ними водоемов) в лесостепную и степную зоны Правобережья в фауне региона присутствуют бореальные виды. «Северные» элементы фауны водных жесткокрылых Саратовской области составляют 20 видов (наибольшая видовая представленность в семействе Dytiscidae), для которых выделено 9 типов ареалов.
\end{abstract}

Ключевые слова: Dytiscidae, Chrysomelidae, Haliplidae, Helophoridae, Heteroceridae, Hydrophilidae, Scirtidae, биоразнообразие, зоогеография, редкие виды.

Благодарности: работа проведена в рамках выполнения государственного задания Министерства науки и высшего образования РФ (№ 121051100109-1).

Для цитирования: Сажнев А.С. 2021. «Северные» элементы в фауне водных жесткокрылых (Insecta: Coleoptera) Саратовской области. Полевой журнал биолога, 3 (2): 154-158. DOI: $10.52575 / 2658-3453-2021-3-2-154-158$

Поступила в редакиию 11 мая 2021 года

\section{"Northern" Elements in Fauna of Water Beetles (Insecta: Coleoptera) of Saratov Oblast}

\author{
Aleksey S. Sazhnev \\ Papanin Institute for Biology of Inland Waters of the Russian Academy of Sciences, \\ 135 Borok vill., Yaroslavl Oblast, 152742, Russia \\ E-mail: sazh@list.ru
}

\begin{abstract}
The geographical location and variety of natural zones (forest-steppe, steppe, semi-desert) of the Saratov Oblast creates unique conditions for the formation of the aquatic beetle fauna in the region. Due to the penetration of island and floodplain forests (and associated water bodies) into the forest-steppe and steppe zones of the Right-bank Volga River, boreal species of aquatic beetles are present in the fauna of the region. The «northern» elements of the aquatic beetle fauna of the Saratov Oblast includes 20 species (mostly species from family Dytiscidae), for which the 9 types of ranges were proposed.
\end{abstract}

Keywords: Dytiscidae, Chrysomelidae, Haliplidae, Helophoridae, Heteroceridae, Hydrophilidae, Scirtidae, biodiversity, zoogeography, rare species.

Acknowledgements: the work was carried out within the framework of the state task of the Ministry of Science and Higher Education of the Russian Federation (No. 121051100109-1).

For citation: Sazhnev A.S. 2021. "Northern" Elements in the Fauna of Water Beetles (Insecta: Coleoptera) of the Saratov Oblast. Field Biologist Journal, 3 (2): 154-158. (In Russian.) DOI: $10.52575 / 2658-3453-2021-3-2-154-158$ 


\section{Введение}

Географическое расположение и разнообразие природных условий Саратовской области, нахождение региона на стыке нескольких зоогеографических провинций, наличие лесостепи и полупустыни как ландшафтных экотонов, трансзональные и интразональные биотопы речных долин, богатая сеть родников и ассоциированные с ними истоковые комплексы, разнообразные солоноводные и эфемерные водоемы степей - все это создает уникальные условия формирования водной колеоптерофауны региона.

В настоящее время для Саратовской области известно 276 видов водных (в широком смысле) жесткокрылых [Сажнев и др., 2010, 2020; Литовкин, Сажнев, 2016; Забалуев и др., 2020; Сажнев, 2020].

\section{Материалы и методы исследования}

Использованы принципы классификации ареалов, изложенные в работах А.Ф. Емельянова [1974, 2018]. При составлении названий типов ареалов отдельно даны названия поясной и секторной составляющей. Высотная составляющая в названии ареалов использовалась только для одного вида с учетом новых данных о его распространении [Prokin et al., 2019].

Распространение видов дано по каталогу жесткокрылых Палеарктики [Catalogue..., 2015, 2016, 2017].

\section{Результаты и их обсуждение}

По характеру географического распространения среди водных жесткокрылых Саратовской области преобладают транспалеарктические и голарктические температные виды, свойственные большей части территории европейской России [Зайцев, 1953]. При этом для фауны Саратовской области (особенно для территории Заволжья) свойственно наличие степных видов и видов более южного, аридного происхождения [Сажнев, 2020]. Также за счет проникновения островных и пойменных лесов и сопутствующих им типов водных объектов в лесостепную и степную зону Правобережья в фауне области присутствуют бореальные виды, основная часть ареала которых проходит значительно севернее, и на территории региона располагается южная граница их распространения, или же эта территория оценивается как «область проникновения» [Бобринский и др., 1946].

Среди «северных» элементов фауны водных жесткокрылых Саратовской области выделяются следующие типы ареалов.

1. Голарктические аркто-суббореальные. Dytiscidae: Agabus fuscipennis (Paykull, 1798), Hydroporus striola (Gyllenhal in Sahlberg, 1826).

2. Голарктические эвбореальные. Dyriscidae: Ilybius erichsoni (Gemminger et Harold, 1868), Hydroporus tristis (Paykull, 1798); Heteroceridae: Augyles intermedius (Kiesenwetter, 1843).

3. Транспалеарктические аркто-суббореальные. Haliplidae: Haliplus sibiricus Motschulsky, 1860.

4. Транспалеарктические эвбореальные. Dytiscidae: Hygrotus quinquelineatus (Zetterstedt, 1828).

5. Суператлантические аркто-суббореальные. Haliplidae: Haliplus confinis Stephens, 1828; Dytiscidae: Ilybius crassus Thomson, 1856, Rhantus exsoletus (Forster, 1771). 1869.

6. Суператлантические эвборео-монтанные. Dytiscidae: Hydroporus incognitus Sharp,

7. Суператлантические эвбореальные. Haliplidae: Haliplus lineolatus Mannerheim, 1844; Dytiscidae: Ilybius ater (DeGeer, 1774), Dytiscus latissimus Linnaeus, 1758, Hydroporus dorsalis (Fabricius, 1787); Hydrophilidae: Enochrus ochropterus (Marsham, 1802); Scirtidae: Contacyphon kongsbergensis (Munster, 1924). 
8. Евро-западносибирские эвбореальные. Helophoridae: Helophorus redtenbacheri Kuwert, 1885.

9. Европейские эвбореальные. Haliplidae: Haliplus varius Nicolai, 1822; Dytiscidae: Agabus uliginosus (Linnaeus, 1761), Graptodytes pictus (Fabricius, 1787).

Таким образом, «северные» элементы фауны водных жесткокрылых области насчитывают 20 видов, имея наибольшую видовую представленность среди Dytiscidae. Находки бореальных видов, в частности из родов Agabus, Ilybius, подсемейства Hydroporinae, семейства Elmidae и др., в регионе еще возможны. Большинство из приведенных видов известны только с севера Саратовской области (лесостепная зона). Находки «северных» видов южнее лесостепи приурочены к пойменным интразональным местообитаниям речных долин pp. Хопер, Волга, Медведица с их притоками, а также к трансзональным биотопам холодноводных родников и ручьев или к болотам. В ряде случаев для видов с высокой вагильностью возможны залеты в несвойственные им местообитания во время расселения. Для проверки достоверности обитания таких видов за пределами лесостепной зоны нужны находки не только имаго, но и личинок.

В связи с этим все виды бореального происхождения, находящиеся на южной границе своего ареала на территории Саратовской области, предложено включить в список видов, заслуживающих особого внимания к их состоянию в окружающей среде, носящий рекомендательный характер. А некоторые из них (например, Dytiscus latissimus) предложено расценивать как особо редкие [Сажнев, 2019], с приоритетом природоохранных мер II - необходимо принятие специальных мер по сохранению вида/подвида/популяции (выполнение конкретной программы сохранения объекта или мероприятия, например, создание искусственных мест размножения, реализация программы по разведению объекта в искусственно созданной среде обитания, создание ООПТ в стации переживания, ограничение конкретной хозяйственной деятельности в местах обитания и т. п.).

\section{Заключение}

Среди «северных» элементов фауны водных жесткокрылых Саратовской области как в секторном (долготном), так и в поясном (широтном) аспектах наиболее представлены виды с широкими ареалами, что объясняется как географическим расположением района исследований в зоне перехода крупных биогеографических областей на равнине, где разграничение ареалов становится дискретным [Городков, 1984], а критические зоогеографические барьеры отсутствуют, так и особенностью воды как среды обитания, которая более однородна и стабильна, а водные объекты определенного типа, являющиеся местообитаниями водных жесткокрылых, имеют более широкое распространение в сравнении с единообразными наземными биотопами [Крыжановский, 2002].

В то же время лесостепь на севере региона и полупустыня (опустыненная степь) на юго-востоке Саратовской области выступают в роли зональных широтных барьеров, которые ограничивают продвижение отдельных видов в обоих направлениях, что отражается на доле как «северных» $(7,2$ \%), так и «южных» $(12,3 \%)$ элементов в фауне водных жесткокрылых Саратовской области. Из этого следует важность и необходимость еще более детального изучения региональной водной колеоптерофауны.

\section{Список литературы}

1. Городков К.Б. 1984. Типы ареалов насекомых тундры и лесных зон европейской части СССР. В кн.: Ареалы насекомых европейской части СССР. Л.: Наука: 3-20.

2. Емельянов А.Ф. 1974. Предложения по классификации и номенклатуре ареалов. Энтомологическое обозрение, 53 (3): 497-522. 
3. Емельянов А.Ф. 2018. Секторная принадлежность типов ареалов, предложенная К.Б. Городковым для северной части Палеарктики. Энтомологическое обозрение, 97 (1): 47-59.

4. Забалуев И.А., Сажнев А.С., Володченко А.Н. 2020. Дополнение к фауне жесткокрылых (Coleoptera) Саратовской области. Сообщение 3. Эверсманния, 61: 5-10.

5. Зайцев Ф.А. 1953. Фауна СССР. Насекомые жесткокрылые. Т. 4. Плавунцовые и вертячки. М.-Л., АН СССР, 377 с.

6. Крыжановский О.Л. 2002. Состав и распространение энтомофаун земного шара. М., Т-во научных изданий КМК 237 с.

7. Литовкин С.В., Сажнев А.С. 2016. Новые данные по распространению и биологии водных жуков (Coleoptera: Haliplidae, Dytiscidae, Helophoridae, Georissidae, Hydrophilidae, Limnichidae, Curculionidae) в России. Евразиатский энтомологический журнал, 15 (1): 17-24.

8. Сажнев А.С. 2019. Водные жесткокрылые (Insecta: Coleoptera) Саратовской области, заслуживающие особого внимания к их состоянию в окружающей среде. Труды Мордовского государственного природного заповедника, 22: 150-159.

9. Сажнев А.С. 2020. Южные элементы в фауне водных жесткокрылых (Coleoptera) Capaтовской области. Энтомологические и паразитологические исследования в Поволжье, 17: 132-135.

10. Сажнев А.С., Аникин В.В., Миронова А.А., Филиппов Д.А. 2020. Дополнение к фауне жесткокрылых (Coleoptera) Саратовской области. Сообщение 4. Эверсманния, 64: 3-5.

11. Сажнев А.С., Прокин А.А., Петров П.Н. 2010. Обзор водных жесткокрылых подотряда Adephaga (Coleoptera: Gyrinidae, Haliplidae, Noteridae, Dytiscidae) Саратовской области (Россия). Известия Харьковского энтомологического общества, 18 (2): 19-31.

12. Catalogue of Palaearctic Coleoptera. 2015. Vol. 2. Revised and updated version. Hydrophiloidea - Staphylinoidea. I. Löbl, D. Löbl (eds.). Leiden-Boston, Brill., 1702 p.

13. Catalogue of Palaearctic Coleoptera. 2016. Vol. 3. Scarabaeoidea, Scirtoidea, Dascilloidea, Buprestoidea, Byrrhoidea. I. Löbl, A. Smetana (eds.). Stenstrup, Brill., 984 p.

14. Catalogue of Palaearctic Coleoptera. 2017. Vol. 1. Archostemata - Myxophaga - Adephaga. Revised and Updated Edition. I. Löbl, D. Löbl (eds.). Stenstrup, Brill., 1443 p.

15. Prokin A.A., Sazhnev A.S., Philippov D.A. 2019. Water beetles (Insecta: Coleoptera) of some peatlands of the North Caucasus. Nature Conservation Research, 4 (2): 57-66. https://dx.doi.org/10.24189/ncr.2019.016.

\section{References}

1. Gorodkov K.B. 1984. Tipy arealov nasekomykh tundry i lesnykh zon yevropeyskoy chasti SSSR [Types of insects areals of tundra and forest zones of the european part of USSR]. In: Arealy nasekomykh yevropeyskoy chasti SSSR [Insects areals of the european part of USSR]. Leningrad, Nauka: $3-20$.

2. Yemel'yanov A.F. 1974. Predlozheniya po klassifikatsii i nomenklature arealov [Proposals on the classification and nomenclature of ranges]. Entomological Review, 53 (3): 11-26.

3. Emeljanov A.F. 2018. Sectorial attribution of the range types proposed by K.B. Gorodkov for the Northern Palaearctic. Entomological Review, 98 (1): 21-32.

4. Zabaluev I.A., Sazhnev A.S., Volodchenko A.V. 2020. New data to the fauna of beetles (Coleoptera) of the Saratov Province. Report 3. Eversmannia, 61: 5-10. (in Russian)

5. Zaitsev F.A. 1953. Fauna SSSR. Nasekomyye zhestkokrylyye. T. 4. Plavuntsovyye i vertyachki [Fauna SSSR. New Series. Coleoptera. Vol. 4. Predaceous diving beetles and whirligig beetles]. Moscow-Leningrad, AN SSSR, 377 p.

6. Kryzhanovskiy O.L. 2002. Sostav i rasprostraneniye entomofaun zemnogo shara [Composition and distribution of entomofaunas of the Globe]. Moscow, KMK Scientific Press Ltd, 237 p.

7. Litovkin S.V., Sazhnev A.S. 2016. New data on the distribution and bilogy of water beetles (Coleoptera: Haliplidae, Dytiscidae, Helophoridae, Georissidae, Hydrophilidae, Limnichidae, Curculionidae) in Russia. Euroasian Entomological Journal, 15 (1): 17-24. (in Russian)

8. Sazhnev A.S. 2019. The water beetles (Insecta: Coleoptera) of Saratov region, which deserve attention to their condition in environment. Proceedings of the Mordovia State Nature Reserve, 22: 150159. (in Russian)

9. Sazhnev A.S. 2020. Southern elements in the fauna of water beetles (Coleoptera) of the Saratov Province. Entomological and Parasitological Investigations in Volga Region, 17: 132-135. (in Russian) 
10. Sazhnev A.S., Anikin V.V., Mironova A.A., Philippov D.A. 2020. New data to the fauna of beetles (Coleoptera) of the Saratov Province. Report 4. Eversmannia, 64: 3-5. (in Russian)

11. Sazhnev A.S., Prokin A.A., Petrov P.N. 2010. Review of water beetles from suborder Adephaga (Coleoptera) of the Saratov region fauna (Russia). The Kharkov Entomological Society Gazette, 18(2): 19-31. (in Russian)

12. Catalogue of Palaearctic Coleoptera. 2015. Vol. 2. Revised and updated version. Hydrophiloidea - Staphylinoidea. I. Löbl, D. Löbl (eds.). Leiden-Boston, Brill., 1702 p.

13. Catalogue of Palaearctic Coleoptera. 2016. Vol. 3. Scarabaeoidea, Scirtoidea, Dascilloidea, Buprestoidea, Byrrhoidea. I. Löbl, A. Smetana (eds.). Stenstrup, Brill., 984 p.

14. Catalogue of Palaearctic Coleoptera. 2017. Vol. 1. Archostemata - Myxophaga - Adephaga. Revised and Updated Edition. I. Löbl, D. Löbl (eds.). Stenstrup, Brill., 1443 p.

15. Prokin A.A., Sazhnev A.S., Philippov D.A. 2019. Water beetles (Insecta: Coleoptera) of some peatlands of the North Caucasus. Nature Conservation Research, 4 (2): 57-66. https://dx.doi.org/10.24189/ncr.2019.016.

\section{ИНФОРМАЦИЯ ОБ АВТОРЕ}

Сажнев Алексей Сергеевич, кандидат биологических наук, старший научный сотрудник Института биологии внутренних вод имени И.Д. Папанина Российской академии наук, п. Борок, Ярославская область, Россия

\section{INFORMATION ABOUT THE AUTHOR}

Sazhnev Aleksey S., Candidate of Biological Sciences, Senior Researcher of Papanin Institute for Biology of Inland Waters of the Russian Academy of Sciences, Borok vill., Yaroslavl Oblast, Russia 